Published in final edited form as:

J Ultrasound Med. 2007 April ; 26(4): 437-444.

\title{
Changes in Fetal Cardiac Geometry with Gestation: Implications for Three-and Four-Dimensional Fetal Echocardiography
}

\author{
Jimmy Espinoza, MD ${ }^{1,2}$, Francesca Gotsch, MD ${ }^{1}$, Juan Pedro Kusanovic, MD ${ }^{1}$, Luís F. \\ Gonçalves, $\mathrm{MD}^{1,2}$, Wesley Lee, $\mathrm{MD}^{3}$, Sonia Hassan, MD $^{1,2}$, Pooja Mittal, MD ${ }^{2}$, Mary Lou \\ Shoen, RDMS ${ }^{1,2}$, and Roberto Romero, MD ${ }^{1,4}$ \\ 1 Perinatology Research Branch, National Institute of Child Health and Human Development, NIH/DHHS, \\ Detroit, Michigan and Bethesda, Maryland, USA \\ 2 Department of Obstetrics and Gynecology, Wayne State University/Hutzel Hospital, Detroit, Michigan, \\ USA \\ 3 Division of Fetal Imaging, William Beaumont Hospital, Royal Oak, Michigan, USA \\ 4 Center for Molecular Medicine and Genetics, Wayne State University, Detroit, Michigan, USA
}

\begin{abstract}
Objective-Three- and 4-dimensional fetal echocardiography can be performed using novel algorithms. However, these algorithms assume that the spatial relationships among cardiac chambers and great vessels are constant throughout gestation. The objective of this study was to determine whether changes in fetal cardiac geometry occur during gestation.
\end{abstract}

Methods-A cross-sectional study was conducted by reviewing 3- and 4-dimensional volume data sets from healthy fetuses obtained between 12 and 41 weeks of gestation. Volume data sets were examined using commercially available software. Parameters measured included angles between: (1) the ductal arch and fetal thoracic aorta; (2) the ductal arch and aortic arch; and (3) the left outflow tract and main pulmonary artery, as seen in the short axis of the heart. The mean angle from the left outflow tract to the short axis was calculated. Nonparametric statistics were used for analysis.

Results-Eighty-five fetuses were included in the study. The angle between the ductal arch and the fetal thoracic aorta decreased with gestational age (Spearman coefficient: $-0.39 ; P<.001$ ). In contrast, the angle between the ductal arch and aortic arch, and the mean angle between the left outflow tract and the short axis of the heart increased with gestational age (Spearman's coefficients: 0.45 and 0.40 respectively; $P<.001$ ).

Conclusion-(1) Changes in fetal cardiac geometry were shown with advancing gestational age. (2) Proposed algorithms for the examination of the fetal heart with 3-dimensional ultrasonography may need to be adapted to optimize visualization of the standard planes before 26 weeks of gestation.

\section{Keywords}

algorithm; cardiac geometry; morphogenesis; 3-dimensional; 4-dimensional; ultrasonography

\footnotetext{
Address correspondence to: Roberto Romero, MD, Perinatology Research Branch, NICHD/NIH/DHHS, Wayne State University/Hutzel Women's Hospital, 3990 John R. Box \#4, Detroit, MI 48201 Phone: (313) 993-2700; Fax: (313) 993-2694, E-mail: warfiela@mail.nih.gov.
} 


\section{INTRODUCTION}

Fetal echocardiography with 3- and 4-dimensional ultrasonography has the potential to reduce the operator dependency that characterizes 2-dimensional ultrasonography. ${ }^{1-10}$ Algorithms using 3- and 4-dimensional ultrasonography proposed thus far allow for the simultaneous display of both outflow tracts, ${ }^{5}$ for the identification of the nature of vascular structures by rotating around $\mathrm{x}$ - and $\mathrm{y}$-axes from reference images obtained in a transverse sweep through the fetal chest, ${ }^{11}$ for the identification of heart defects using color or power Doppler ultrasonography and with spatiotemporal image correlation (STIC), $10,12,13$ or for the examination of the fetal heart using automated multiplanar imaging. ${ }^{8}$ More recently, a combination of tomographic ultrasonographic imaging and STIC was described for the examination of transverse planes of the heart ${ }^{14-16}$ and the simultaneous display of the 3 -vessel and trachea view, the 4-chamber view, as well as both outflow tracts. ${ }^{17}$ These algorithms assume that the spatial relationships among cardiac chambers and great vessels are constant throughout gestation. However, if this assumption is not correct, the algorithms may need to be adjusted to account for changes in cardiac and vascular spatial relationships with advancing gestational age. The objective of this study was to examine whether changes in fetal cardiac geometry occur during gestation.

\section{Material and Methods}

Three- and four-dimensional volume data sets of the fetal heart were acquired with transverse sweeps through the fetal chest in 85 patients examined at our ultrasound unit. Inclusion criteria were: (1) singleton gestations; (2) gestational age between 12 and 41 weeks; and (3) a normal heart by fetal echocardiography. Patients with fetal anomalies and those whose volume data sets did not include the upper mediastinum were excluded. Examinations were performed with STIC (Voluson 730 Expert, release BTO4; GE Healthcare, Milwaukee, WI) using hybrid mechanical and curved array transducers (RAB 4-8P, RAB 4-8L, RAB 2-5P, and RAB 2-5L). Acquisition time ranged from 7.5 to 15 seconds and the angle of acquisition ranged between $20^{\circ}$ and $40^{\circ}$, depending on fetal motion and gestational age. All patients were enrolled in research protocols approved by the Institutional Review Board of the National Institute of Child Health and Human Development and by the Human Investigation Committee of Wayne State University. All women signed a written informed consent prior to participation in the study.

After removal of patient identifiers, examinations were retrospectively reviewed offline using 4DView software version 5.0 (GE Medical Systems, Kretztechnik, Zipf, Austria). All volume data sets were acquired with B-mode imaging, and only 1 volume data set per patient was included in the study. Preference was given to volume data sets considered by the investigator to be of the highest quality, according to the following characteristics: (1) the fetal spine was positioned between 3- and 9-o'clock, minimizing the possibility of shadowing from the ribs or spine; and (2) minimal or no motion artifacts were observed on the sagittal plane.

\section{Description of angle measurements}

All volume data sets were displayed using the multiplanar modality, which allowed for the simultaneous display of images in 3 orthogonal planes (panels A, B and C). Angle measurements were performed as follows:

1. The volume data sets were adjusted to display the 4-chamber view in panel A, where the fetal aorta was aligned with the crux of the heart in the vertical plane. The reference dot was then positioned on the aorta, allowing the visualization of the coronal view of the descending aorta in panel C (Figure 1A). 
2. In panel $\mathrm{C}$, the image was rotated to display the aorta in a vertical position, when necessary. This allowed for the visualization of the longitudinal view of the ductal arch in panel B as previously described (Figure 1A). ${ }^{17}$

a. Angle between the ductal arch and aortic arch: This angle was measured by clicking in panel A, selecting the Rotation $\mathrm{Z}$ option, and scrolling to the left. The image in panel B (initially displaying the ductal arch plane) was rotated until the long axis of the aortic arch was visualized as previously described. 18 The angle displayed in the Rotation $\mathrm{Z}$ option was then recorded (Figure 1B and Video 1).

b. Angle between the ductal arch and thoracic aorta: The angle between the ductal arch and the thoracic aorta was measured in panel B (sagittal plane). This panel was magnified, and the Measure and Generic Angle options were selected. The angle between a parallel line to the flattest portion of the ductal arch and a line parallel to the descending aorta was measured using the Angle 3 Point tool (Figure 2). When the flat portion of the ductal arch could not be visualized, the line was drawn parallel to the portion of the ductal arch closest to the descending aorta.

c. Angle between the left outflow tract and the short axis of the heart (right outflow tract): The left outflow tract was displayed in panel A, and the reference dot was placed on the aorta, above the insertion of the aortic valve, as described by Gonçalves et al. ${ }^{5}$ This angle was measured by clicking in panel A, selecting the Rotation Y option, and scrolling the bar to the left until the short axis of the heart was visualized in panel A. The angle displayed in the Rotation Y option was then recorded (Figure 3). We continued to scroll on the $\mathrm{Y}$ axis until the anatomic components of the short axis of the aorta could not be visualized in panel A (ie, the aorta was seen as a circle in the center of the section; the pulmonary valve lay anterior and cranial to the aortic valve; the ductal arch was visualized; and the pulmonary artery branched inferiorly into the duct and the left pulmonary artery). ${ }^{19}$ This second angle displayed in the Rotation Y option was also recorded. The mean of these two angle measurements was then calculated for each patient (Video 2).

\section{Statistical analysis}

Kolmogorov-Smirnov test was used to test for normality. Spearman tests were performed to determine the correlations between the gestational age at the time of ultrasonography and the 3 angle measurements described above. $P<.05$ was considered significant. Statistical analysis was performed with SPSS 12.0 for Windows (SPSS, Chicago, IL).

\section{Results}

Eighty-five volume data sets were reviewed offline. Table 1 indicates that angle measurements changed with gestational age, mostly before 26 weeks of gestation. The wide variation in angle measurements may represent normal individual variation among fetuses at different gestational ages. The angle between the ductal arch and the thoracic aorta significantly decreased with advancing gestational age (Spearman correlation coefficient: $-0.39 ; P<.001$; Figure 4). In contrast, the angle between the ductal and aortic arch (Spearman correlation coefficient: 0.45; $P<.001$; Figure 5) and the mean angle between the left and right outflow tracts (Spearman correlation coefficient: $0.40 ; P<.001$; Figure 6 ) increased with gestational age. 


\section{Discussion}

Our results demonstrated changes in cardiac geometry with advancing gestational age, particularly before 26 weeks of gestation. These observations are novel and indicate that the spatial relationships among cardiac chambers and great vessels are not constant throughout gestation.

Our finding that the angle between the ductal arch and the thoracic aorta decreases with gestational age indicates that the axis of the heart is more horizontal early in gestation. This is consistent with the observation of Allan et $\mathrm{al}^{20}$ that the apex of the heart in the fetus is more cranially displaced than in the neonate, particularly in the second trimester. Although the authors proposed that this may be due to the relatively large size of the liver, ${ }^{20}$ it is possible that the differential growth of other intra-thoracic organs (eg, thymus and lungs) may also account for some of the changes in cardiac geometry observed herein.

Cardiac morphogenesis is a complex process by which 2 parallel tubular structures, the lateral endocardial tubes, form a single primitive heart tube. ${ }^{21} \mathrm{~A}$ central event during embryonic development of the heart is cardiac looping, a highly conserved process that begins at human embryonic day $23 .^{22}$ This happens even before the heart tube has completed its formation. 23 During looping, the heart tube elongates $21,24,25$ and undergoes "ballooning," 26 which allows progressive differentiation of the "primitive cardiac chambers". 27 Cardiac looping rearranges regions of the heart tube so they are positioned for proper formation and the alignment of chambers, valves, and septa. ${ }^{22,23}$ This contributes to the conversion of the cardiovascular system from a circuit in series to a parallel circulation. ${ }^{22}$

Cardiac looping involves 2 processes: $\mathrm{C}$ and $\mathrm{S}$ looping. ${ }^{28}$ During normal $\mathrm{C}$ looping, the primitive heart changes from a straight tube into a $\mathrm{C}$-shaped tube because of ventral bending and rightward rotation. ${ }^{29}$ Conversely, during S-looping, the atrium moves superior to the ventricle, creating the final form of the heart. ${ }^{29}$ The last phase involves a process of "wedging," which brings the anterior (arterial) and posterior (venous) poles in proximity. ${ }^{23} \mathrm{Abnormal}$ looping had been proposed to participate in the mechanisms of abnormal cardiac morphogenesis in atrioventricular discordance, double-inlet left ventricle, double-outlet right ventricle, and transposition of the great arteries. ${ }^{23}$

The results of this study indicate that the spatial relationships of cardiac chambers and great vessels continue to change with advancing gestational age, even after embryonic cardiac morphogenesis. Prospective longitudinal studies are required to determine whether these changes are the result of differential growth of intracardiac and/or extracardiac structures.

The findings presented herein are novel and have important implications for 3- and 4dimensional algorithms proposed for the examination of the fetal heart. These algorithms may need to be adjusted to account for variations in cardiac geometry with advancing gestational age.

\section{Supplementary Material}

Refer to Web version on PubMed Central for supplementary material.

\section{Acknowledgements}

This research was supported by the Intramural Research Program of the National Institute of Child Health and Human Development, NIH, DHHS. 


\section{Reference List}

1. Nelson TR, Pretorius DH, Sklansky M, Hagen-Ansert S. Three-dimensional echocardiographic evaluation of fetal heart anatomy and function: acquisition, analysis, and display. J Ultrasound Med 1996;15:1-9. [PubMed: 8667477]

2. Deng J, Gardener JE, Rodeck CH, Lees WR. Fetal echocardiography in three and four dimensions. Ultrasound Med Biol 1996;22:979-986. [PubMed: 9004421]

3. Sklansky MS, Nelson TR, Pretorius DH. Usefulness of gated three-dimensional fetal echocardiography to reconstruct and display structures not visualized with two-dimensional imaging. Am J Cardiol 1997;80:665-668. [PubMed: 9295008]

4. DeVore GR, Falkensammer P, Sklansky MS, Platt LD. Spatio-temporal image correlation (STIC): new technology for evaluation of the fetal heart. Ultrasound Obstet Gynecol 2003;22:380-387. [PubMed: 14528474]

5. Goncalves LF, Lee W, Chaiworapongsa T, et al. Four-dimensional ultrasonography of the fetal heart with spatiotemporal image correlation. Am J Obstet Gynecol 2003;189:1792-1802. [PubMed: 14710117]

6. Maulik D, Nanda NC, Singh V, et al. Live three-dimensional echocardiography of the human fetus. Echocardiography 2003;20:715-721. [PubMed: 14641376]

7. Vinals F, Poblete P, Giuliano A. Spatio-temporal image correlation (STIC): a new tool for the prenatal screening of congenital heart defects. Ultrasound Obstet Gynecol 2003;22:388-394. [PubMed: 14528475]

8. Abuhamad A. Automated multiplanar imaging: a novel approach to ultrasonography. J Ultrasound Med 2004;23:573-576. [PubMed: 15154522]

9. Sklansky M. New dimensions and directions in fetal cardiology. Curr Opin Pediatr 2003;15:463-471. [PubMed: 14508293]

10. Chaoui R, Hoffmann J, Heling KS. Three-dimensional (3D) and 4D color Doppler fetal echocardiography using spatio-temporal image correlation (STIC). Ultrasound Obstet Gynecol 2004;23:535-545. [PubMed: 15170792]

11. DeVore GR, Polanco B, Sklansky MS, Platt LD. The 'spin' technique: a new method for examination of the fetal outflow tracts using three-dimensional ultrasound. Ultrasound Obstet Gynecol 2004;24:72-82. [PubMed: 15229920]

12. Goncalves LF, Romero R, Espinoza J, et al. Four-dimensional ultrasonography of the fetal heart using color Doppler spatiotemporal image correlation. J Ultrasound Med 2004;23:473-481. [PubMed: 15098864]

13. Goncalves LF, Espinoza J, Romero R, et al. A systematic approach to prenatal diagnosis of transposition of the great arteries using 4-dimensional ultrasonography with spatiotemporal image correlation. J Ultrasound Med 2004;23:1225-1231. [PubMed: 15328439]

14. DeVore GR, Polanko B. Tomographic ultrasound imaging of the fetal heart: a new technique for identifying normal and abnormal cardiac anatomy. J Ultrasound Med 2005;24:1685-1696. [PubMed: 16301725]

15. Goncalves LF, Espinoza J, Romero R, et al. Four-dimensional ultrasonography of the fetal heart using a novel Tomographic Ultrasound Imaging display. J Perinat Med 2006;34:39-55. [PubMed: 16489885]

16. Paladini D, Vassallo M, Sglavo G, Lapadula C, Martinelli P. The role of spatio-temporal image correlation (STIC) with tomographic ultrasound imaging (TUI) in the sequential analysis of fetal congenital heart disease. Ultrasound Obstet Gynecol 2006;27:555-561. [PubMed: 16619376]

17. Espinoza J, Kusanovic JP, Goncalves LF, et al. A novel algorithm for comprehensive fetal echocardiography using 4-dimensional ultrasonography and tomographic imaging. J Ultrasound Med 2006;25:947-956. [PubMed: 16870887]

18. Bega G, Kuhlman K, Lev-Toaff A, Kurtz A, Wapner R. Application of three-dimensional ultrasonography in the evaluation of the fetal heart. J Ultrasound Med 2001;20:307-313. [PubMed: 11316308]

19. Allan L. Technique of fetal echocardiography. Pediatr Cardiol 2004;25:223-233. [PubMed: 15360115] 
20. Allan LD, Tynan MJ, Campbell S, Wilkinson JL, Anderson RH. Echocardiographic and anatomical correlates in the fetus. Br Heart J 1980;44:444-451. [PubMed: 7426207]

21. Moorman A, Webb S, Brown NA, Lamers W, Anderson RH. Development of the heart: (1) formation of the cardiac chambers and arterial trunks. Heart 2003;89:806-814. [PubMed: 12807866]

22. Kathiriya IS, Srivastava D. Left-right asymmetry and cardiac looping: implications for cardiac development and congenital heart disease. Am J Med Genet 2000;97:271-279. [PubMed: 11376438]

23. Ramsdell AF. Left-right asymmetry and congenital cardiac defects: getting to the heart of the matter in vertebrate left-right axis determination. Dev Biol 2005;288:1-20. [PubMed: 16289136]

24. Mjaatvedt $\mathrm{CH}$, Nakaoka T, Moreno-Rodriguez R, et al. The outflow tract of the heart is recruited from a novel heart-forming field. Dev Biol 2001;238:97-109. [PubMed: 11783996]

25. Waldo KL, Kumiski DH, Wallis KT, et al. Conotruncal myocardium arises from a secondary heart field. Development 2001;128:3179-3188. [PubMed: 11688566]

26. Christoffels VM, Habets PE, Franco D, et al. Chamber formation and morphogenesis in the developing mammalian heart. Dev Biol 2000;223:266-278. [PubMed: 10882515]

27. Gittenberger-de Groot AC, Bartelings MM, Deruiter MC, Poelmann RE. Basics of cardiac development for the understanding of congenital heart malformations. Pediatr Res 2005;57:169-176. [PubMed: 15611355]

28. Manner J. Cardiac looping in the chick embryo: a morphological review with special reference to terminological and biomechanical aspects of the looping process. Anat Rec 2000;259:248-262. [PubMed: 10861359]

29. Taber LA. Biophysical mechanisms of cardiac looping. Int J Dev Biol 2006;50:323-332. [PubMed: 16479500] 

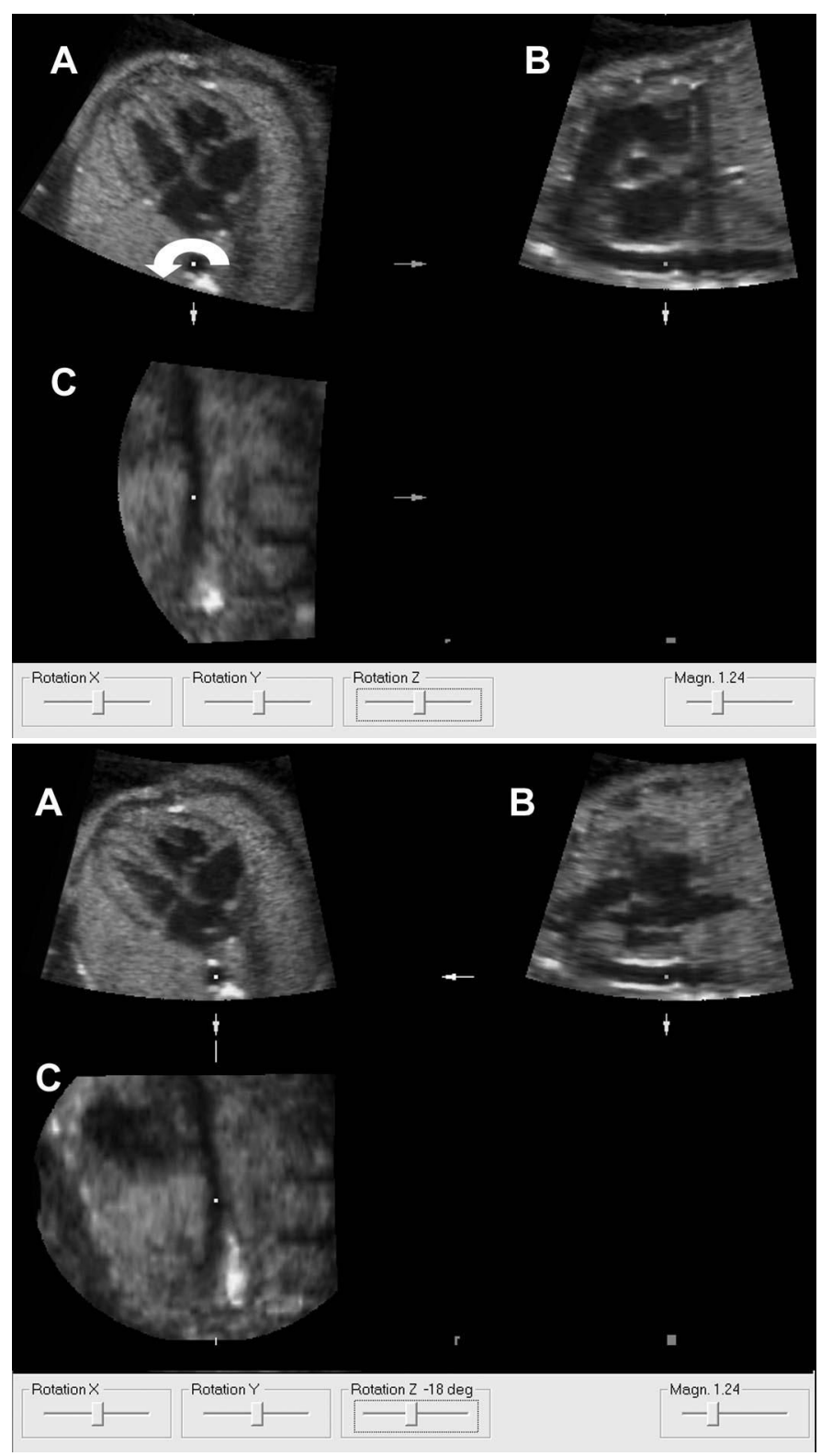

Figure 1.

After clicking in panel A, the Rotation $\mathrm{Z}$ option was selected, and the bar was scrolled to the left. The image in panel B, initially displaying the ductal arch plane (A), was rotated until the long axis of the aortic arch was visualized $(\mathbf{B})$. The angle displayed in the Rotation $\mathrm{Z}$ bar was recorded. 


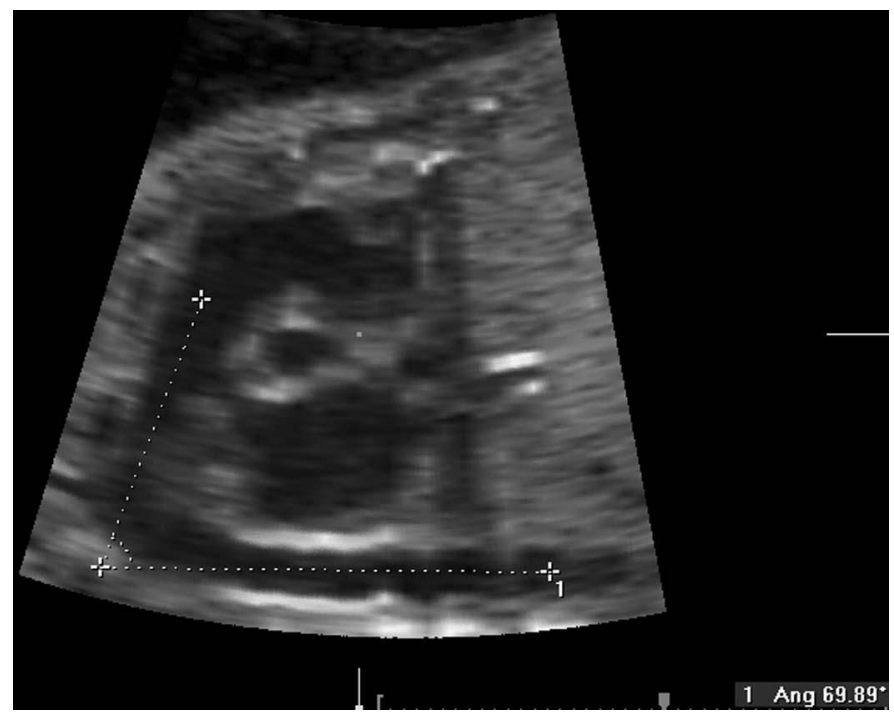

Figure 2.

The angle between the ductal arch and the thoracic aorta was measured in the sagittal plane (Figure 1A, panel B). The angle between a parallel line to the flattest portion of the ductal arch and a line parallel to the descending aorta was measured. 

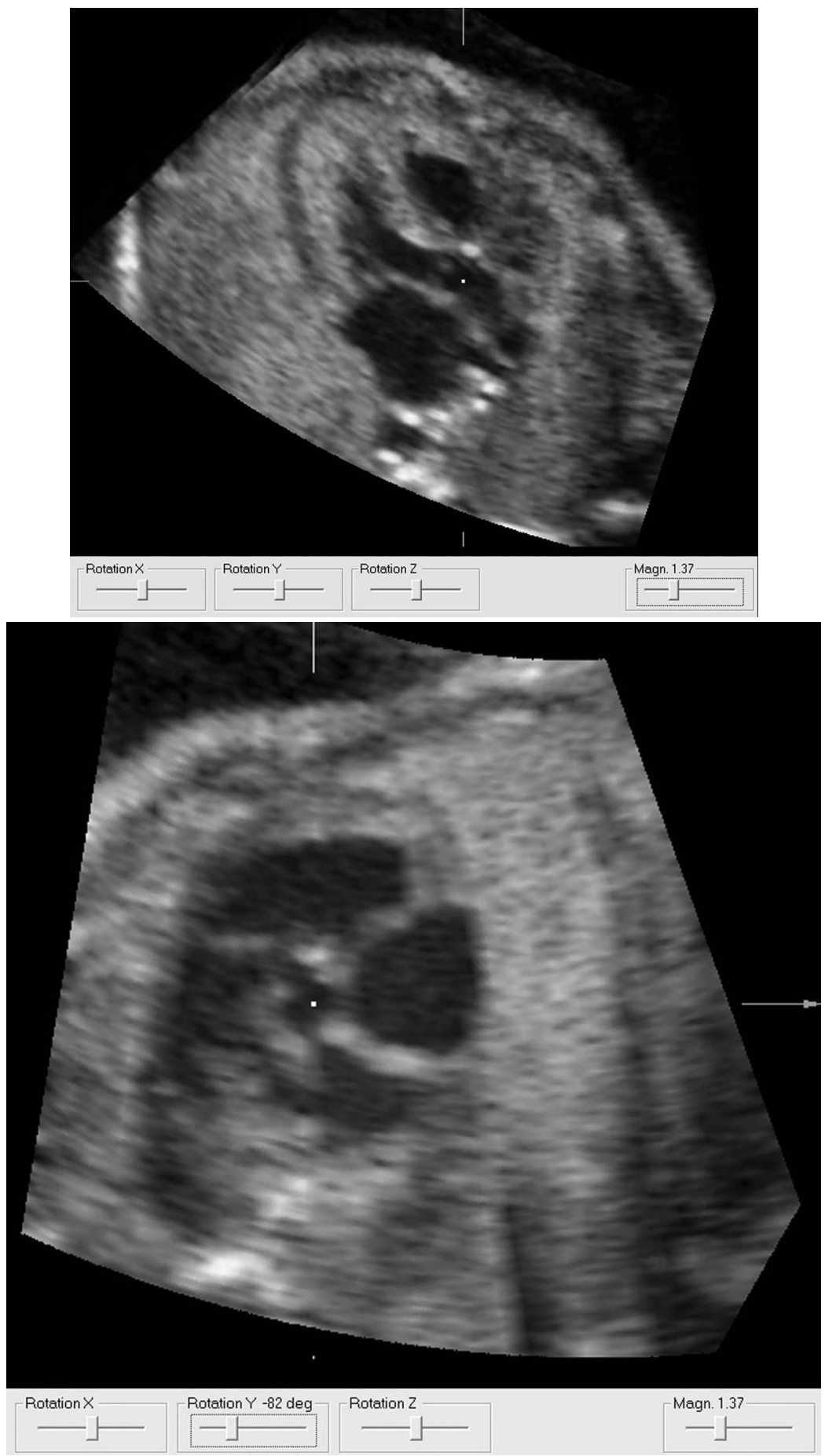

Figure 3.

A, The left outflow tract was displayed in panel A; the image was magnified; and the Rotation Y option was selected. B, The Rotation Y bar was scrolled to the left until the short axis of the heart was visualized, and the angle displayed in the Rotation Y bar was recorded. 


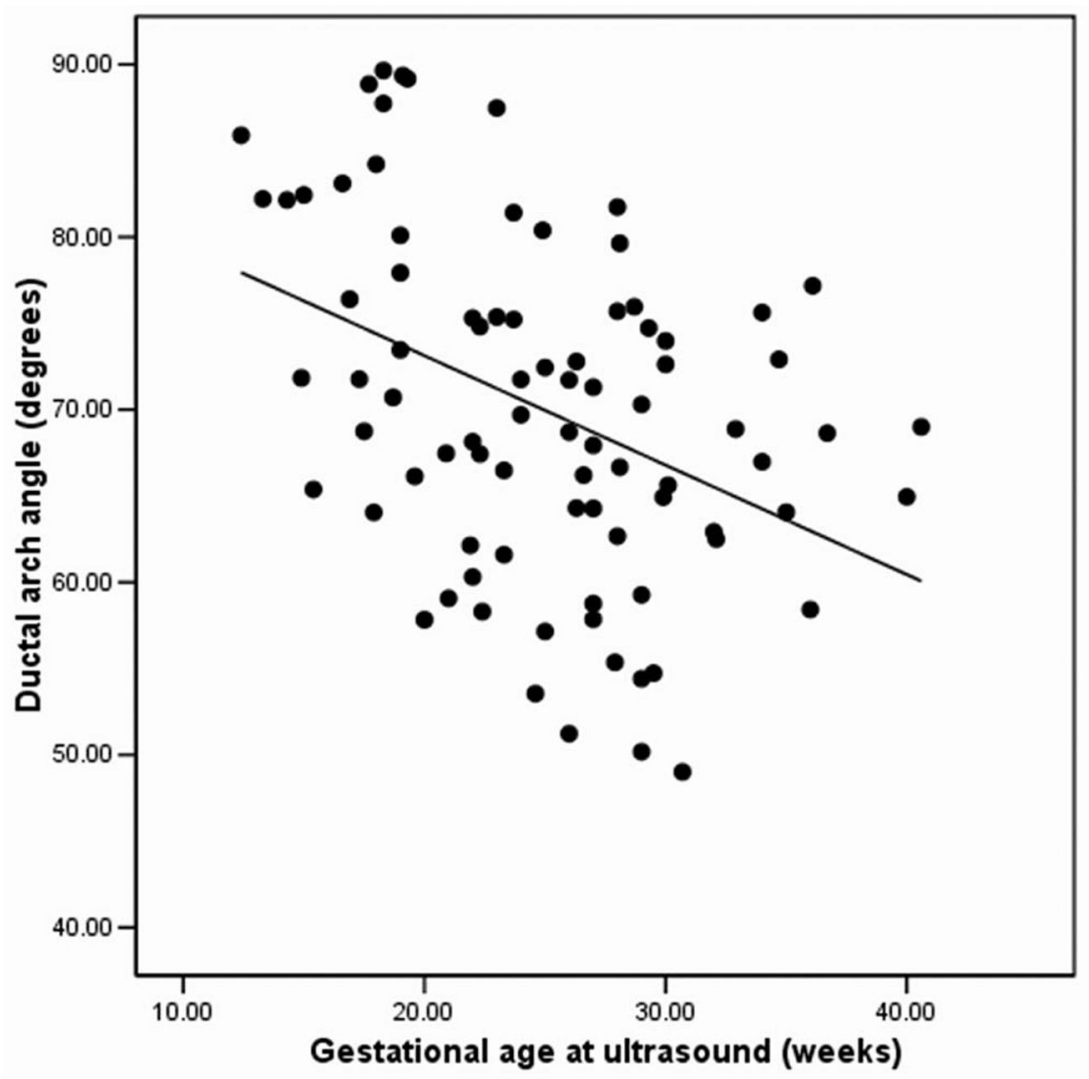

Figure 4.

The angle between ductal arch and thoracic aorta significantly decreased with advancing gestational age (Spearman correlation coefficient, $-0.39 ; P<.001$ ). The lines represents the mean values. 


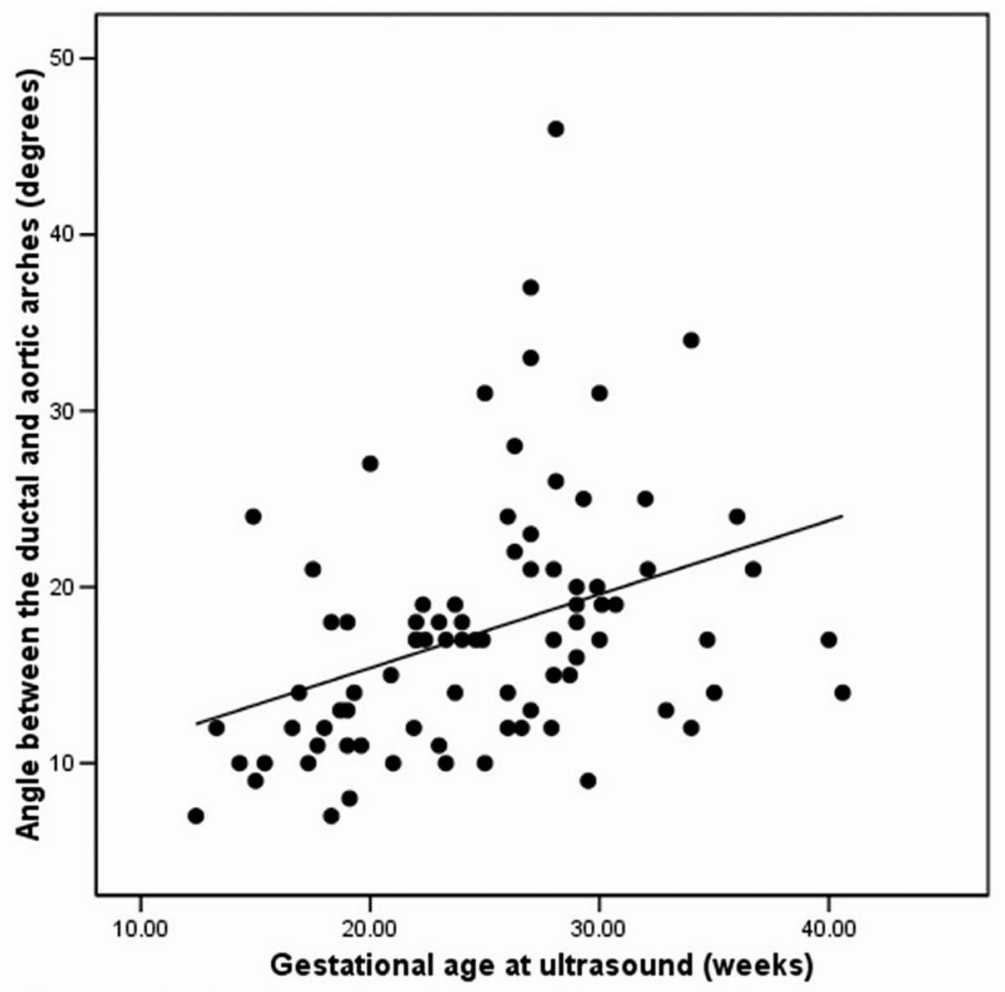

Figure 5.

The angle between the ductal arch and the aortic arch significantly increased with gestational age (Spearman correlation coefficient, $0.45 ; P<.001$ ). The line represents the mean values. 


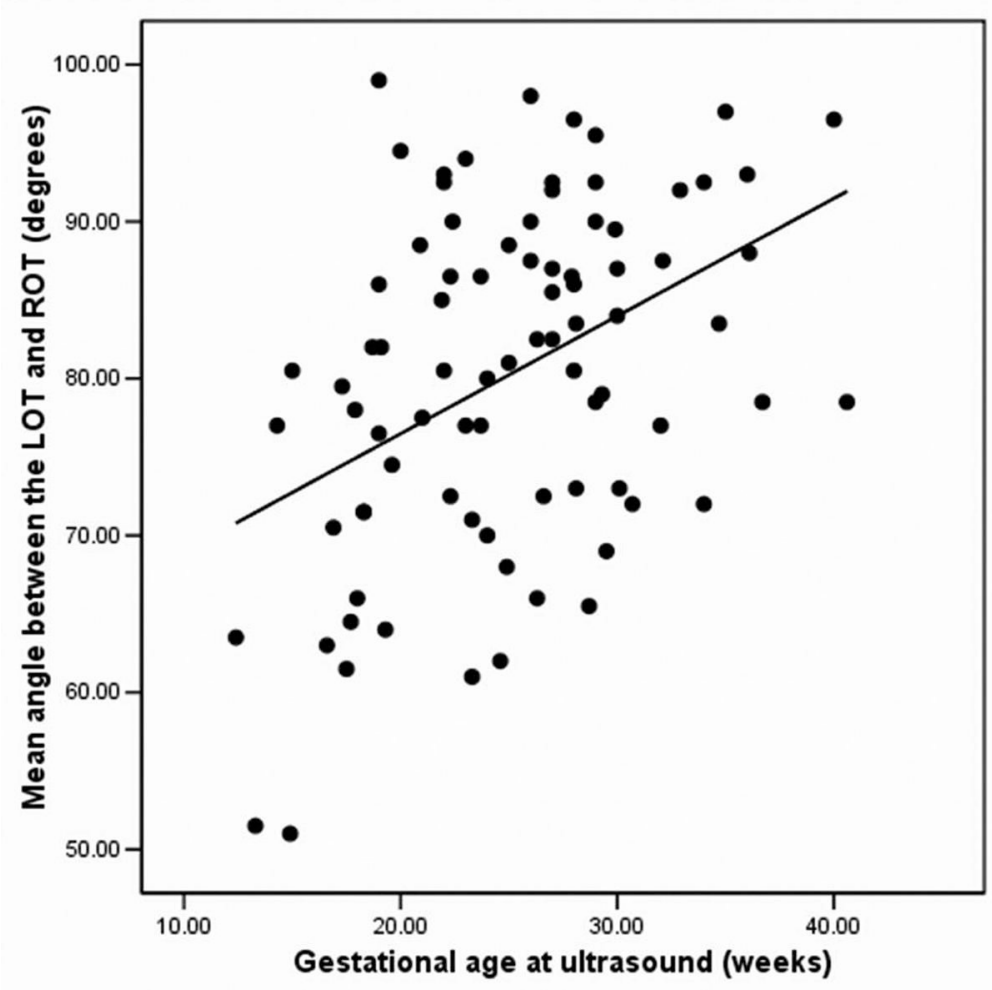

Figure 6.

The mean angle between the left outflow tract (LOT) and right outflow tract (ROT, as seen in the short axis of the heart) increased with gestational age (Spearman correlation coefficient, $0.40 ; P<.001)$. The lines represent the mean values. 
Table 1

Angles Between Anatomic Planes of the Fetal Heart and Great Vessels

\begin{tabular}{llcc}
\hline Gestational Age, wk & $\begin{array}{l}\text { Ductal Arch and Thoracic } \\
\text { Aorta, }\end{array}$ & $\begin{array}{c}\text { Ductal Arch and Aortic } \\
\text { Arch, }\end{array}$ & $\begin{array}{c}\text { Mean Angle Between the Left }^{\circ} \\
\text { Outflow Tract and Short Axis }^{\circ}\end{array}$ \\
\hline$<15(\mathrm{n}=6)$ & $82.2(65.4-85.9)$ & $10(7-24)$ & $57.5(34.5-80.5)$ \\
$15-20.9(\mathrm{n}=18)$ & $77.1(57.8-89.7)$ & $13(7-27)$ & $75.5(61.5-99)$ \\
$21-25.9(\mathrm{n}=20)$ & $68.9(53.6-87.5)$ & $17(10-31)$ & $80.3(61-94)$ \\
$26-30.9(\mathrm{n}=29)$ & $66.2(49.0-81.7)$ & $19(9-46)$ & $85.5(65.5-98)$ \\
$31-35(\mathrm{n}=8)$ & $65.5(58.4-75.6)$ & $19(12-34)$ & $89.8(72-97)$ \\
$>36(\mathrm{n}=4)$ & $68.8(64.6-77.2)$ & $17(14-21)$ & $83.3(78.5-96.5)$ \\
\hline
\end{tabular}

Values are expressed as median (range). 